\title{
Design, Implementation and Testing of an Automatic Power Management System for Residential Stand-alone Microgrids with Hybrid Power Supply
}

\author{
Bruno Belvedere, Michele Bianchi, Alberto Borghetti, Mario Paolone \\ Faculty of Engineering, University of Bologna, 40136 Bologna, Italy \\ (e-mail: \{bruno.belvedere;michele.bianchi;alberto.borghetti;mario.paolone\}@unibo.it).
}

\begin{abstract}
The paper presents an automatic power management system (PMS) designed for the on-line operation of an experimental low voltage microgrid equipped with two power supplies, a $\mathrm{kW}$-class fuel cell (FC) and a photovoltaic (PV) module emulator, along with a 100-Ah battery storage system, all connected to a $230 \mathrm{VAC}$ node. The connections of the various components to the common AC bus make use of power inverters with specific functionalities: the FC inverter controls the power production taking into account the FC limitations and requirements, the inverter of the PV emulator tracks its maximum power operating point, whilst, in islanded operating conditions, the bidirectional converter of the battery controls the voltage and frequency of the AC node. The AC node feeds electric active and reactive loads able to reproduce arbitrary and programmable profiles. The automatic PMS is implemented in a real time microcontroller and it is able to provide both the microgrid monitoring and supervisory control during grid-connected and islanded conditions and the FC power scheduling throughout various operating modes. The paper describes also the experimental investigation aimed at assessing the dynamic characteristics of the stand-alone microgrid equipped with the developed PMS.
\end{abstract}

Keywords: digital control, microcontroller, electrical microgrids, electrical power coordination, fuel cell, photovoltaic emulator, battery.

\section{INTRODUCTION}

There is a general interest for the utilization of $\mathrm{kW}$-class fuel cells (FCs) in residential applications (Sammes and Boersma, 2000). Indeed, compared with conventional small generators, Proton Exchange Membrane (PEM) FCs promise higher efficiency, clean and silent operation and cost-effective supply of power. Recently, Erdinc and Uzunoglu (2010) provide a review of different architectures of systems powered by PEM FCs, also in combined use with other power supply and energy storage units in order to build socalled hybrid systems. Stand-alone systems assume particular importance as they can also be used as back-up units in case of network service failure. The same paper also presents a review of various energy management approaches proposed in the literature in order to cope with the different characteristics of multiple power generators. Among them, for the case of a PEM FC-battery system for electric vehicle applications, Thounthong et al. (2008) propose a cascade control of the FC-current, battery-current, and battery stateof-charge (SOC) with a limitation function of the DC-link voltage. For residential applications, the analysis of both advantages and control strategies of hybrid energy storage systems composed by regenerative fuel cells integrated with batteries or ultra-capacitors have been presented by Maclay et al. (2006 and 2007) in order to exploit the different energy density and power density of the components.

This work was supported in part by the Ministero dell'Istruzione, dell'Università e della Ricerca as a project of the PRIN 2007 programme.
Indeed, in stand-alone systems equipped with electrochemical batteries, the estimation of the battery SOC represents one of the most critical operation parameters. In this respect, a SOCbased control has also been designed and implemented for the automatic operation of the experimental microgrid developed at the authors' laboratory (Belvedere, et al., 2007 and Belvedere, et al., 2009). As shown in Fig. 1, the microgrid includes a PEM FC able to provide a $4.5 \mathrm{~kW}$ electrical output and $4.7 \mathrm{~kW}$ thermal output, a $500 \mathrm{~W}$ photovoltaic (PV) module emulator and a $100 \mathrm{Ah}$ lead-acid battery storage system, all connected to a $230 \mathrm{~V} \mathrm{AC}$ bus through inverters with specific characteristics ${ }^{1}$. The inverter of the PEM FC controls the power production taking into account the FC limitations and requirements, the one of the PV emulator tracks its maximum power operating point, whilst the $4.2 \mathrm{~kW}$ bidirectional converter of the battery is able to control the voltage and the frequency of the AC bus when disconnected from the external network (Strauss and Engler, 2003). The $\mathrm{AC}$ bus feeds electric active and reactive loads that reproduce programmable profiles through separate on-load tap-changer transformers.

\footnotetext{
${ }^{1}$ In the literature, different schemes are also proposed and analysed in which the various components of the hybrid power supply are connected to a common DC bus, e.g. (Jain and Agarwal , 2008) and (Jiang and Fahimi, 2010).
} 


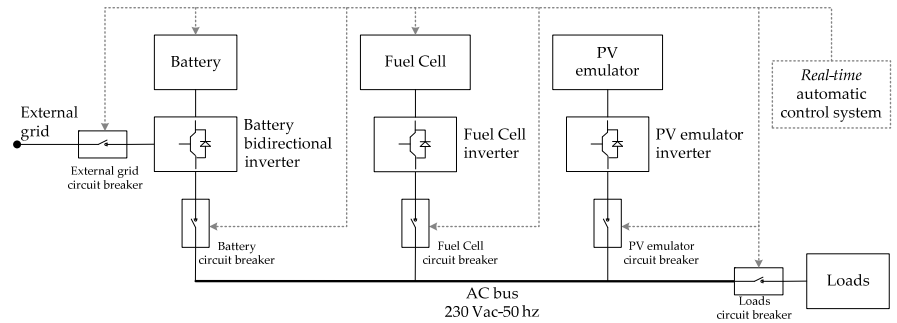

Fig. 1. Architecture of the microgrid.

The paper aims at describing the functions of the developed automatic Power Management System (PMS) implemented into a microcontroller (equipped with a Field Programmable Gate Array - FPGA). Moreover, it presents the results of the experimental investigation aimed at assessing the dynamic characteristics of the stand-alone microgrid under various initial battery SOC levels and electric load profiles.

The structure of the paper is the following. Section 2 describes the PMS functionalities developed for the control of the FC output with reference to stand-alone operating conditions of the microgrid. Section 3 presents the experimental results obtained during the PMS actions for different load profiles. Section 4 presents the results of the PMS and microgrid transient response following a sudden and complete disconnection of the electric load (load rejection). Section 5 is devoted to the conclusions.

\section{PMS FUNCTIONS FOR THE CONTROL OF THE FC OUTPUT IN ISLANDED OPERATING CONDITIONS}

The developed test microgrid can be operated both in gridconnected and stand-alone operating conditions. The passage from grid-connected to stand-alone conditions is assured by the battery inverter (Strauss and Engler, 2003).

We here focus on the PMS functions implemented for the stand-alone operation of the microgrid. In order to limit the number of shutdown and start-up manoeuvres of the FC, the main objective of the PMS action is the regulation of the battery SOC by means of the FC output. The PMS operates the FC start-up, if it is not yet in operation, when the SOC of the battery reaches a minimum value $\left(S O C_{\text {start }}\right)$, whilst operates the FC shutdown in case the battery is completely charged. Otherwise, the PMS tries to regulate the value of the battery SOC to an intermediate value $\left(S O C^{*}\right)$ that allows the battery to compensate the variations of both the electric load and the PV production.

The various permutations of PMS actions are listed in (Belvedere, et al., 2009). The next two subsections focus on the description of the procedure implemented for the continuous estimation of the battery SOC and the control algorithm of the SOC that incorporates the functions that avoids the intervention of the protection voltage relays of the battery inverter.

\subsection{Battery SOC estimation}

In what follows, the value of the lead-acid battery SOC is assumed as the difference between the rated battery capacity and the net actual level of charge divided by the rated value of the battery capacity. Several SOC models have been proposed in the literature (e.g., Piller, et al., 2001, Pop, et al., 2005), which can be grouped in the following categories: i) measurement of electrolyte specific gravity, ii) battery current time-integration, iii) battery impedance/resistance estimation, iv) measurement of the battery open circuit voltage, v) models that take into account the electrolyte temperature, discharge rate and other batteries parameters. Additionally, an accurate SOC estimation needs to take into account the battery environmental conditions, with particular reference to its temperature, as well as the battery behaviour at different discharge rates. A combination of methods (ii), (iv) and (v) is implemented by the following general equation

$$
\operatorname{SOC}(t)=\frac{C\left(t_{0}\right)-\alpha(I, \theta) \int_{t_{0}}^{t} i(t) d t}{C(I, \theta)}
$$

where $C(I, \theta)$ is the battery capacity for a constant current discharge rate $I$ at electrolyte temperature $\theta, C\left(t_{0}\right)$ is the battery capacity at time $t_{0}, i(t)$ is the instantaneous value of the battery current (both charge/discharge), $\alpha$ is the efficiency coefficient associated to battery charge and discharge efficiency (assumed equal to one).

The initial state of the SOC (with zero battery current condition maintained for few hours) is based on the known correlation between lead-acid battery open circuit voltage and the electrolyte density (e.g., Linden, 1995) in the assumption that appropriate use/maintenance of the battery has been always granted. Fig. 2 shows such a correlation for the $100 \mathrm{Ah}-48 \mathrm{~V}$ lead-acid battery storage system used in the experimental microgrid $\left(20^{\circ} \mathrm{C}\right.$ reference temperature). The initial SOC value provided in Fig. 2 takes into account the battery temperature by means of the same linear approximation also adopted to correct the SOC estimation during the battery charge/discharge cycles.

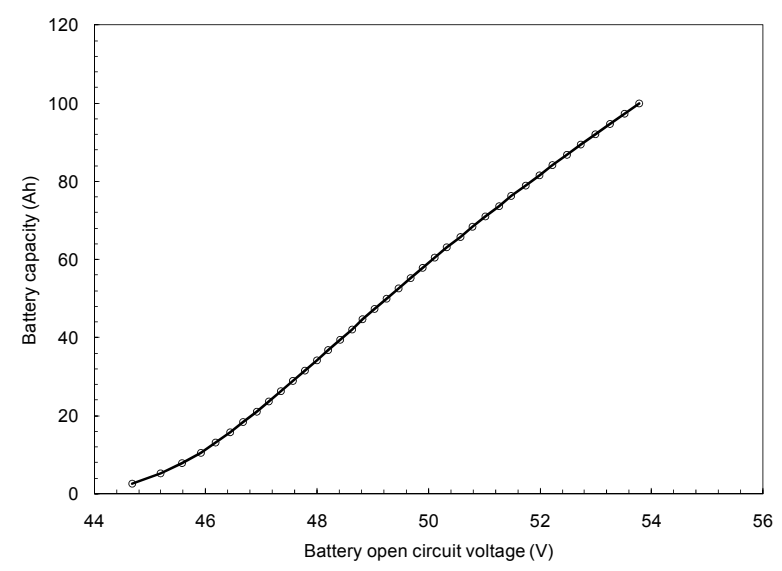

Fig. 2. Relationship between the estimation of the initial battery capacity $C\left(t_{0}\right)$ and the battery open circuit voltage.

The PMS includes a suitable procedure in order to apply (1) for the case of non-constant charge/discharge rates. We assume to know the array of values $C\left(I^{*}\right)=\left(C\left(I_{0}^{*}\right), \ldots, C\left(I_{k}^{*}\right), \ldots, C\left(I_{n}^{*}\right)\right)$ that defines the intervals of the battery capacity at various discharge rates $I_{k}^{*}$ at temperature $\theta^{*}$. The data are typically provided by the 
manufacturer, as shown in Fig. 3 for the 100 Ah lead-acid battery utilized in the microgrid. Data refer to a reference temperature equal to $20^{\circ} \mathrm{C}$ and to a battery voltage-per-cell final value equal to $1.75 \mathrm{~V}$.

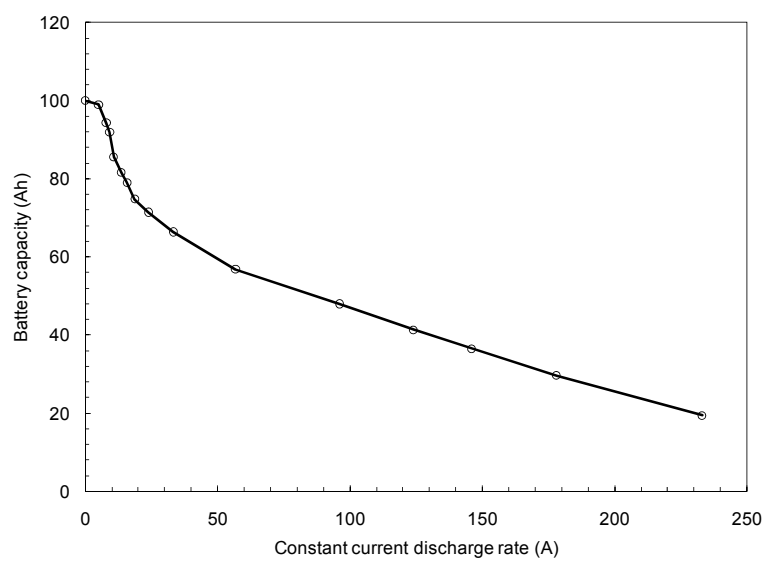

Fig. 3. Battery capacity $C\left(I^{*}\right)$ as a function of different constant current discharge rates.

The PMS calculates the average charge/discharge battery current $\tilde{I}_{T, f_{s}}$ into a specific time window $T$ by averaging the measured battery current $I_{\text {batt }}$ sampled at frequency $f_{s}$ (in our case $f_{s}=5 \mathrm{~Hz}$, and $T=2 \mathrm{~s}$ ). Let assume that the SOC has already estimated at time $t-\Delta t$ and let consider that $\tilde{I}_{T, f_{s}} \in\left[C\left(I_{k}^{*}\right), C\left(I_{k+1}^{*}\right)\right]$, calculated in $[t-\Delta t, t]$, then equation

(1) can be written as:

$$
S O C(t)=\frac{C(t-\Delta t)-\left(\tilde{I}_{T, f_{s}}(t-\Delta t)+\tilde{I}_{T, f_{s}}(t)\right) \frac{\Delta t}{2}}{C\left(\tilde{I}_{T, f_{s}}, \theta\right)}
$$

where

$$
C\left(\tilde{I}_{T, f_{s}}, \theta\right)=\frac{C\left(I_{k}^{*}\right)+C\left(I_{k+1}^{*}\right)}{2}
$$

The averaging of the charge/discharge battery current over a sufficient large time window $T$ allows to assume an equivalent constant discharge ratio, $\tilde{I}_{T, f_{s}}$, for which the application of (1) is still valid. A discontinuity in the SOC estimation could take place when the average charge/discharge battery current $\tilde{I}_{T, f_{s}}$ moves from a discharge rate interval to a different one, i.e., when, at time $t$, $\tilde{I}_{T, f_{s}} \in\left[C\left(I_{j}^{*}\right), C\left(I_{j+1}^{*}\right)\right]$ with subscript $j$ different from $k$ of (3). In order to avoid discontinuity in the SOC estimation, the value of battery capacity $C(t-\Delta t)$ in (2) is replaced by the product between the rated battery capacity associated with the new equivalent discharge rate $\tilde{I}_{T, f_{s}}$ multiplied by the value of the SOC estimated at $t-\Delta t$, namely:

$$
C(t-\Delta t)=C\left(\tilde{I}_{T, f_{s}}, \theta\right) \operatorname{SOC}(t-\Delta t)
$$

The rated capacity $C\left(\tilde{I}_{T, f_{s}}, \theta\right)$ in (2) and (4) takes into account the capacity drift with the temperature adopting a linear approximation (e.g. Linden, 1995)

$$
C\left(\tilde{I}_{T, f_{s}}, \theta\right)=C\left(\tilde{I}_{T, f_{s}}, \theta^{*}\right)\left(1+\beta\left(\theta-\theta^{*}\right)\right)
$$

For the adopted lead-acid battery, coefficient $\beta$ has been assumed equal to 0.006 (as suggested by the manufacturer) and the reference temperature $\theta^{*}$ is equal to $20^{\circ} \mathrm{C}$.

\subsection{Control of the SOC and limitation function of the battery voltage}

The PMS has been conceived to control the battery SOC. In particular, the FC output is controlled in order to track a target SOC value, $S C^{*}$, which is pre-determined as an average SOC level that allows to: i) keep the storage system into a state that is able to provide energy in case of load request, or receive energy in case of photovoltaic production and ii) minimize the number of FC start up and shutdown manoeuvres. When the SOC is close to $S O C^{*}$ the FC output is expected to follow the load profile.

In view of the above, the PMS control has been developed with a state-chart structure. The main operating modes are defined by the following four intervals associated to the battery SOC:

$$
\begin{array}{ll}
\text { 1. } & S O C \leq S O C_{\min }^{*} ; \\
\text { 2. } & S O C_{\min }^{*}<S O C<S O C^{*} ; \\
\text { 3. } & S O C^{*} \leq S O C<S O C_{\max }^{*} ; \\
\text { 4. } & S O C_{\max }^{*} \leq S O C .
\end{array}
$$

Values $S O C_{\text {min }}^{*}$ and $S O C_{\text {max }}^{*}$ define a relatively narrow band around the $S O C^{*}$ value.

In operating modes 2 and 3, the PMS sets the reference of the internal FC power output control, $P_{\mathrm{FC}, \text { ref, }}$, in order to add or subtract an adjustment, proportional to the SOC deviation from the $S O C^{*}$ value, to measured net power $P_{\mathrm{PV} \text {-load }}$ (being $P_{\mathrm{PV}-\mathrm{load}}$ the difference between the power produced by the PV unit and the active power load request).

In operating modes 1 and 4 the PMS sets the $P_{\mathrm{FC}, \text { ref }}$ value in order to bring the SOC within the band defined by $S O C_{\text {min }}^{*}$ and $S O C^{*}{ }_{\max }$ values, i.e. to quickly charge or discharge the battery, respectively. The speed of the charge/discharge process depends, also, on the load request.

In all operating modes, the calculation of the $P_{\mathrm{FC}, \mathrm{ref}}$ value is also affected by the limited range of the battery voltage $\left[V_{\text {batt }}^{\min }, V_{\text {batt }}^{\max }\right]$ that assures the reliable operation of the battery power converter. In case the battery voltage exceeds the one of the limits, an internal relay of the battery inverter may disconnect this component, causing a microgrid blackout. As the battery voltage varies depending on the injected/absorbed current and its rate of change, the $P_{\mathrm{FC}, \text { ref }}$ value is adjusted by the outputs of the undervoltage and overvoltage limiters illustrated in Fig. 4. 
Taking into account all these aspects, for each of the four PMS operating modes previously defined, the control of the $P_{\mathrm{FC}, \text { ref }}$ is defined by the following equations: operating mode 1

$$
P_{\mathrm{FC}, \text { ref }}=-P_{\mathrm{PV} \text {-load }}+\left(P_{\mathrm{FC}}^{\mathrm{max}}+P_{\mathrm{PV} \text {-load }}\right) \cdot\left(1-u_{\text {max }}\right)
$$

operating mode 2

$P_{\mathrm{FC}, \text { ref }}=-P_{\mathrm{PV} \text {-load }}+\left(P_{\mathrm{FC}}^{\mathrm{max}}+P_{\mathrm{PV} \text {-load }}\right) \cdot \frac{S O C^{*}-S O C}{S O C^{*}-S O C_{\text {min }}^{*}} \cdot\left(1-u_{\text {max }}\right)(7)$

operating mode 3

$P_{\mathrm{FC}, \text { ref }}=-P_{\mathrm{PV} \text {-load }}+\left(P_{\mathrm{FC}}^{\min }+P_{\mathrm{PV} \text {-load }}\right) \cdot \frac{S O C-S O C^{*}}{S O C_{\text {max }}^{*}-S O C^{*}} \cdot\left(1-u_{\text {min }}\right)(8)$

operating mode 4

$P_{\mathrm{FC}, \text { ref }}=-P_{\mathrm{PV} \text {-load }}+\left(P_{\mathrm{FC}}^{\mathrm{min}}+P_{\mathrm{PV} \text {-load }}\right) \cdot\left(1-u_{\text {min }}\right)$

with the constraint

$P_{\mathrm{FC}}^{\min } \leq P_{\mathrm{FC}, \mathrm{ref}} \leq P_{\mathrm{FC}}^{\max }$

where $P_{\mathrm{FC}}^{\min }$ and $P_{\mathrm{FC}}^{\max }$ are the lower and the upper limits of the FC power output, equal to $500 \mathrm{~W}$ and $4500 \mathrm{~W}$, respectively.

The values of $u_{\min }$ and $u_{\max }$ (limited in the interval [0,1]) are defined by means of PID controls shown in Fig. 4 that operate when the battery voltage is below or above two threshold values $V_{\text {batt,nom }}^{\min }$ and $V_{\text {batt,nom }}^{\max }$, larger than $V_{\text {batt }}^{\min }$ and lower than $V_{\text {batt }}^{\max }$, respectively. The PIDs set-points and process variables are defined in per unit of the difference between each voltage threshold value, $V_{\text {batt } n \text { nom }}^{\min }$ or $V_{\text {batt,nom }}^{\max }$, and the relevant voltage limit, $V_{\text {batt }}^{\min }$ or $V_{\text {batt }}^{\max }$.

The values of the parameters two PIDs have been chosen identical and equal to: $K_{p}=1, T_{i}=30 \mathrm{~s}, T_{d}=0.06 \mathrm{~s}$.

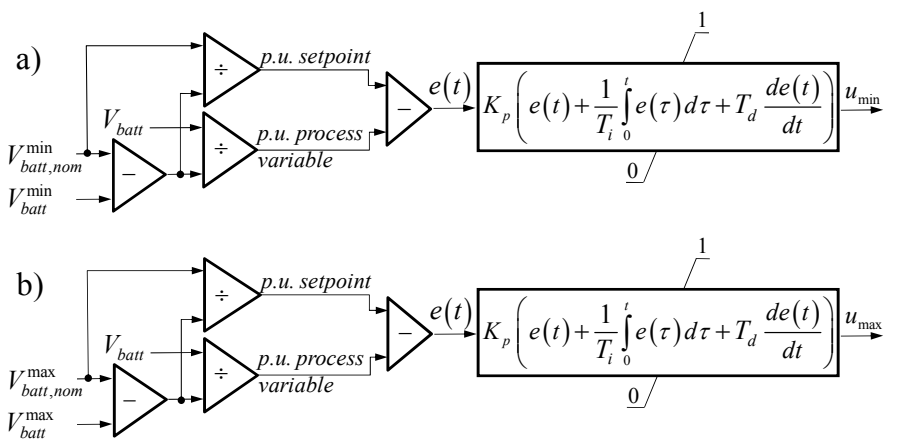

Fig. 4 Battery undervoltage (a) and overvoltage (b) limiters that adjust the $P_{\mathrm{FC} \text {,ref }}$ output.

\subsection{Microcontroller implementation}

The PMS functions are implemented into a real-time microcontroller equipped with an FPGA that allows its interface with analog/digital input/output signals. The FPGA consists of a Xilinx Virtex II 3000 device characterized by $3 \mathrm{M}$ gates implementing 16-bit ADC converters, operating at a sampling frequency of $100 \mathrm{kHz}$, used to measure the system variables. The microcontroller runs three main cycles, namely: i) data-acquisition that calculates the system state variables $\left(V_{\text {batt }}, I_{\text {batt }}, P_{\mathrm{FC}, \text { ref }}, P_{\text {load,PV }}\right)$, ii) $\mathrm{SOC}$ estimation and iii) $P_{\mathrm{FC}, \text { ref }}$ control. Each cycle is executed within a specific time loop: $200 \mathrm{~ms}$ for the data-acquisition and SOC estimation, $5000 \mathrm{~ms}$ for the $P_{\mathrm{FC} \text {,ref }}$ control.

The value of the time step loop relevant to the $P_{\mathrm{FC}, \text { ref }}$ control has been chosen equal to $5000 \mathrm{~ms}$ as the $\mathrm{FC}$ internal control is able to adjust the real FC power output with a time constant of few seconds.

The value of the data-acquisition and SOC estimation time step loops have been chosen equal to $200 \mathrm{~ms}$ in order to adequately monitor the power exchange dynamic phenomena that take place into both FC and microgrid electrical network. Each $200 \mathrm{~ms}$, the data acquisition loop uses the $100 \mathrm{kHz}-$ digitalized sampled data to calculate the system state variables.

\section{EXPERIMENTAL INVESTIGATION OF THE STAND- ALONE OPERATION}

This section illustrates some experimental tests carried out in order to verify the PMS operation with reference to the standalone case. Two different conditions have been tested with reference to the initial SOC value, namely SOC value lower (Test $a$ ) and greater (Test $b$ ) than $S O C^{*}$. Both tests have been performed with the following parameters: $S O C^{*}=$ $50 \%, S O C_{\min }^{*}=47.5 \%, S O C_{\max }^{*}=52.5 \%, S O C_{\text {start }}=45 \%$, $V_{\text {batt,nom }}^{\min }=44 \mathrm{~V}, \quad V_{\text {batt,nom }}^{\max }=54 \mathrm{~V}$, being $V_{\text {batt }}^{\min }=41 \mathrm{~V}$ and $V_{\text {batt }}^{\max }=63 \mathrm{~V}$ the undervoltage and overvoltage relay thresholds of the battery inverter, respectively.

The tests refer to two different load profiles both characterized by the same duration of $1380 \mathrm{~s}$ whilst the same photovoltaic production profile has been adopted.

As mentioned, the photovoltaic generator consists of a PVarray emulator and a separated inverter that also performs the maximum power point tracking function. The emulator simulates the voltage-current characteristics of the solar array by means of the exponential model described in (Britton et al., 1993). The parameters used by such a model are the following: $V_{o c}$ (solar array cells open circuit voltage), $I_{s c}$ (solar array cells short circuit current), $V_{m p}$ and $I_{m p}$ (voltage and current of the solar array cells in correspondence of the maximum power).

The load emulator consists of two separated transformers equipped with on-load tap changers (400 tap positions) that control the voltage (in the range between 0 and $230 \mathrm{~V}$ ) applied to a $9 \Omega$ resistive and $12 \mathrm{mH}$ inductive loads respectively. The load control is realized by an hysteresis regulator that adjust the transformer tap changer positions in order to track active and reactive power set points within an hysteresis window of $\pm 100 \mathrm{~W}$ or Var.

Table 1 shows the parameters used in the PV-array emulator to define its production profile and Table 2 shows the active load power set points for the two tests. The reactive power set point is not reported, as the power factor is kept constant and equal to 0.85 . 
Table 1. Set points of the $\mathbf{P V}$-array emulator.

\begin{tabular}{|c|c|c|c|c|}
\hline Changing time $(\mathrm{s})$ & $V_{o c}(\mathrm{~V})$ & $I_{s c}(\mathrm{~A})$ & $V_{m p}(\mathrm{~V})$ & $I_{m p}(\mathrm{~A})$ \\
\hline 0 & 0 & 0 & 0 & 0 \\
\hline 10 & 60 & 6.4 & 51.5 & 5.6 \\
\hline 40 & 60 & 5.6 & 51.0 & 4.9 \\
\hline 130 & 60 & 7.2 & 52.0 & 6.3 \\
\hline 210 & 60 & 8.0 & 52.5 & 7.0 \\
\hline 900 & 60 & 4.0 & 50.0 & 3.5 \\
\hline
\end{tabular}

Table 2. Set points of the load emulator

\begin{tabular}{|c|c|c|}
\cline { 2 - 3 } \multicolumn{1}{c|}{} & Test $a$ & Test $b$ \\
\hline Changing time (s) & $P_{\text {load }}(\mathrm{W})$ & $P_{\text {load }}(\mathrm{W})$ \\
\hline 0 & 0 & 0 \\
\hline 10 & 3500 & 2500 \\
\hline 110 & 500 & 5000 \\
\hline 290 & 1500 & 3000 \\
\hline 340 & 0 & 3000 \\
\hline 390 & 2500 & 4500 \\
\hline 490 & 3000 & 4000 \\
\hline 540 & 500 & 5000 \\
\hline 590 & 1200 & 3500 \\
\hline 690 & 500 & 5000 \\
\hline 940 & 1500 & 3000 \\
\hline
\end{tabular}

\subsection{Test a}

In what follows we refer to the results of Fig. 5 that shows some of the quantities measured during the test. The SOC value and the current measured at the battery DC terminals are shown in Fig. 5a). The FC output, the power at the battery inverter $\mathrm{AC}$ terminals and the $P_{\mathrm{PV}-\text { load }}$ profile are shown in Fig. 5b). Fig. 5c) shows the battery DC voltage and PID output $u_{\max }$ that limits the $P_{\mathrm{FC}, \text { ref }}$ value using as a reference the parameter $V_{\text {batt,nom }}^{\max }=54 \mathrm{~V}$ in order to avoid the overvoltage relay intervention (as described in Fig. 4b).

During the test, the lead-acid battery temperature is different from the reference temperature $\theta^{*}=20^{\circ} \mathrm{C}$. The battery temperature increases from $22.5^{\circ} \mathrm{C}$ at the beginning of the test to about $25^{\circ} \mathrm{C}$ at the end.

The initial SOC value is equal to $46.2 \%$ and the $\mathrm{FC}$ is not in operation. The first step of the load profile of $3.5 \mathrm{~kW}$ and 2.2 kvar rapidly reduces the battery SOC to the $S O C_{\text {start }}$ value, causing the automatic FC start-up at $t=62 \mathrm{~s}$. The FC start-up lasts around $45 \mathrm{~s}$. During such an interval, the FC absorbs the power needed by its auxiliaries' from the battery. Once the FC starts to produce power, the PMS acts to maximize the FC output in order to quickly charge the battery (operating mode $1)$, without violating the maximum $\mathrm{DC}$ voltage value, as set by eq. (6). At $t=552 \mathrm{~s}$, the battery charge exceeds the $S O C_{\text {min }}^{*}$ value. The PMS now controls the FC output in order to follow the $P_{\mathrm{PV}-\text { load }}$ profile and to adjust the battery charge to the $S O C^{*}$ value (eq. (7), corresponding to operating mode 2).

During this test, the total load request (taking into account also the PV production) is equal to $0.414 \mathrm{kWh}$, the $\mathrm{FC}$ production is $0.844 \mathrm{kWh}$ and its net electric efficiency with reference to the hydrogen lower heating value is equal to
$37.4 \%$ (the stack production is $1.123 \mathrm{kWh}$, the auxiliaries' energy consumption is $0.131 \mathrm{kWh}$ and the hydrogen consumption is $0.758 \mathrm{Nm}^{3}$ ), the energy accumulated in the battery is $0.358 \mathrm{kWh}(0.427 \mathrm{kWh}$ is the net energy absorbed by the battery storage system from the microgrid).
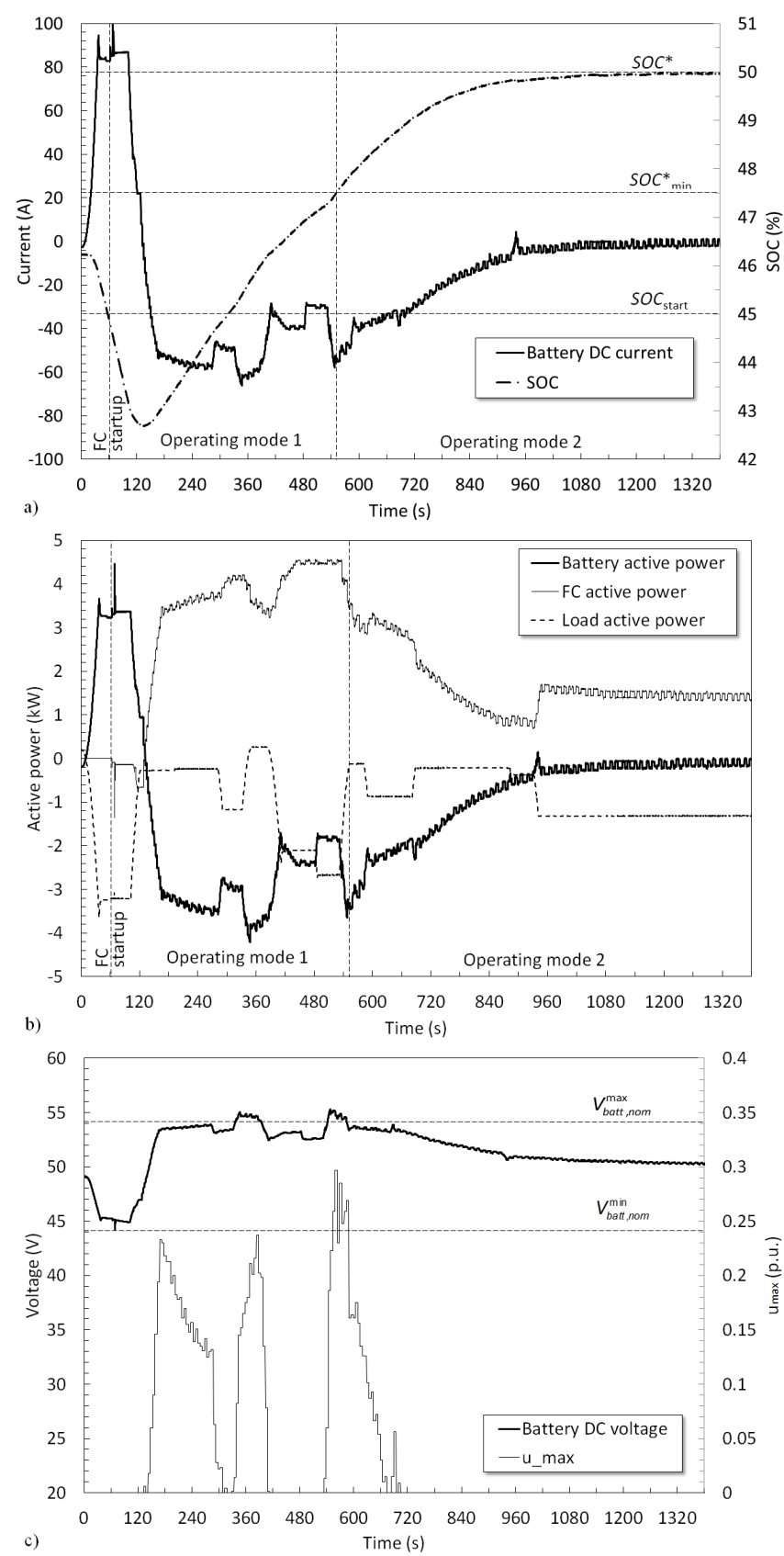

Fig. 5 Test $a$ : a) battery SOC and current, b) powers (FC, battery, and net load), c) battery voltage and overvoltage limiter output.

\subsection{Test $b$}

Fig. 6 shows some of the measured quantities during the test: the SOC and the battery current profiles in Fig 6a), the FC output and the battery power exchange in Fig. 6b) together with the $P_{\mathrm{PV}-\text { load }}$ profile, whilst Fig. 6c) shows the DC battery voltage and the $u_{\max }$ PID output. 

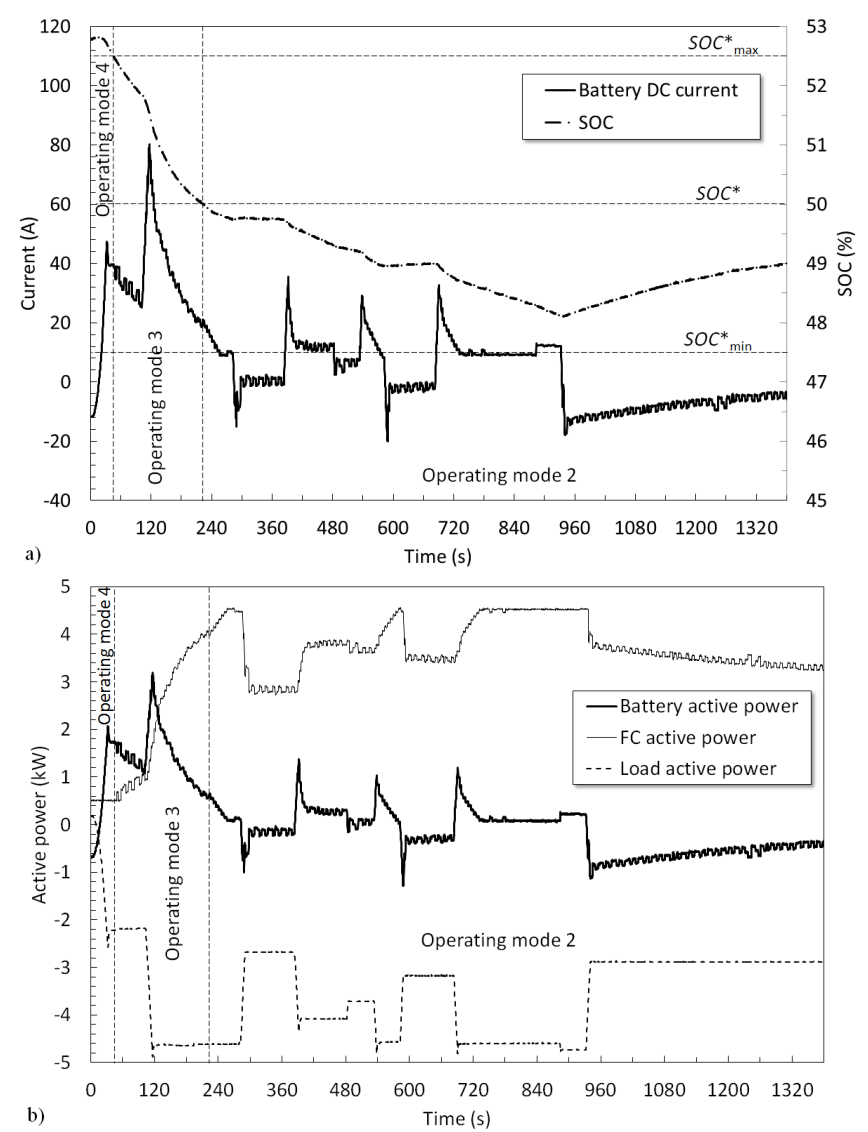

b)

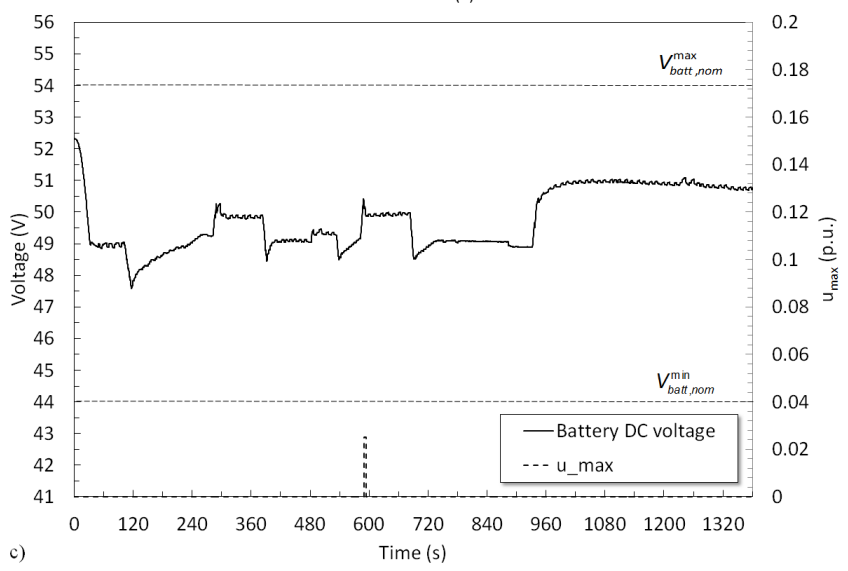

Fig. 6 Test $b$ : a) battery SOC and current, b) powers (FC, battery, net load), c) battery voltage and PID output.

The battery SOC value at the beginning of test $b$ is equal to $52.7 \%$, i.e. greater than $S O C_{\text {max }}^{*}$. The $\mathrm{FC}$ is operating at the minimum value $P_{\mathrm{FC}}^{\min }=500 \mathrm{~W}$ and the battery temperature varies from about $22^{\circ} \mathrm{C}$ to about $25^{\circ} \mathrm{C}$.

As set by operating model 4 , i.e. eq. (9), the PMS initially acts quickly to discharge the battery by reducing the $P_{\mathrm{FC}}$ as low as possible, taking into account also the limit of the undervoltage relay of the battery inverter. At $t=45 \mathrm{~s}$, the battery SOC is below the $S O C_{\text {max }}^{*}$ threshold and then the PMS controls the FC output in order to follow the load variations with a limited shortage so to adjust the battery charge to the $S O C^{*}$ value (eq. (8), corresponding to operating mode 3). However, due to both the slow FC dynamic and a load value greater than $P_{\mathrm{FC}}^{\max }$, at $t=223 \mathrm{~s}$ the battery $\mathrm{SOC}$ becomes lower than $S O C^{*}$ and afterwards the PMS adjusts the $P_{\mathrm{FC}, \text { ref }}$ to charge the battery (operating mode 2), taking into account the $V_{\text {batt }}^{\max }$ limit. As shown in Fig. 6c), the output of the overvoltage limiter becomes greater than zero at $t=$ $590 \mathrm{~s}$ for a short period, because of the PID derivative action.

During this test, the total load request (taking into account also the PV production) is equal to $1.386 \mathrm{kWh}$, the $\mathrm{FC}$ production is $1.376 \mathrm{kWh}$ and its net electric efficiency with reference to the hydrogen lower heating value is equal to $37.6 \%$ (the stack production is $1.807 \mathrm{kWh}$, the auxiliaries' energy consumption is $0.182 \mathrm{kWh}$ and the hydrogen consumption is $1.231 \mathrm{Nm}^{3}$ ), the energy provided by the battery is $0.108 \mathrm{kWh}(0.013 \mathrm{kWh}$ is the net energy provided by the battery storage system to the microgrid).

\section{LOAD REJECTION MANOUVER}

In order to assess the capability of the PMS and the FC to keep the battery DC voltage below the overvoltage relay threshold of the battery inverter, various tests of complete load disconnections have been carried out.

As an example, Fig. 7a) shows the measured profiles of load, battery and FC outputs and $P_{\mathrm{FC} \text {,ref }}$ set by the PMS action. Fig. 7b) shows the corresponding measured profiles of the battery voltage and current, together with overvoltage limiter output $u_{\max }$.

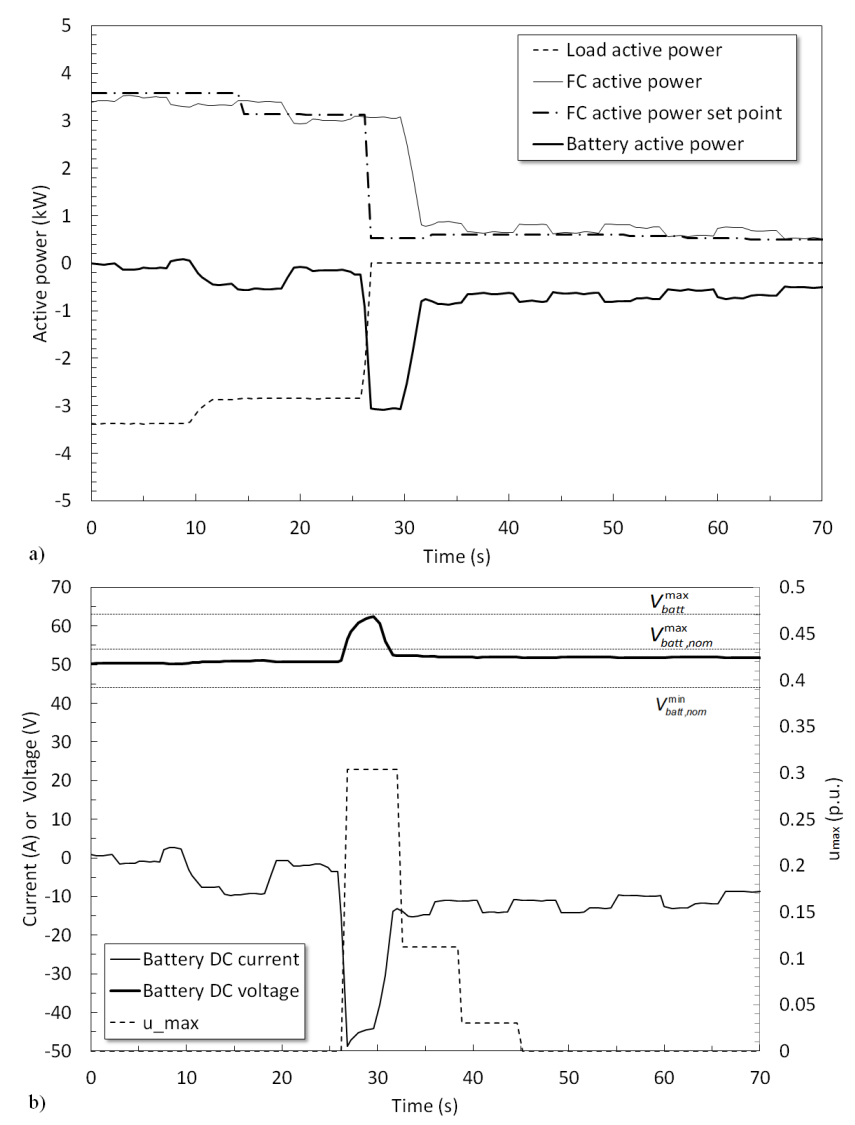

Fig. 7 Load rejection test: a) powers ( $P_{\mathrm{FC}, \text { ref }}, \mathrm{FC}$ output, battery, and net load), b) battery voltage, current and overvoltage limiter output $u_{\max }$. 
The test starts with a $3 \mathrm{~kW}$ load and a SOC value equal to $49.6 \%$ corresponding to PMS operating mode 2 . In such an initial condition, the PMS sets the $P_{\mathrm{FC} \text {,ref }}$ just above the load level. At $t=26 \mathrm{~s}$, the main circuit breaker of the loads is opened. Fig. 7a) shows the quick PMS response essentially due to the overvoltage limiter action shown in Fig. 7b). The communication delay between the PMS and the FC is estimated to be about $3 \mathrm{~s}$. The FC internal dynamic also limits the steepness of the FC output reduction. However, at $t=32 \mathrm{~s}$, the FC output is reduced to $800 \mathrm{~W}$, allowing the limitation of the voltage battery to $62.4 \mathrm{~V}$ and avoiding the overvoltage relay intervention. The total transient lasts for less than $6 \mathrm{~s}$ after which the battery voltage settles to $52 \mathrm{~V}$.

\section{CONCLUSIONS}

The PMS described in the paper allows the reliable standalone operation of a $\mathrm{kW}$-class residential microgrid fed by a controllable FC and a PV unit. It allows following both the load and PV production variations by acting to the power control of the FC. In order to limit the number of start-up and shutdown manoeuvres of the FC, the main objective of the PMS actions is the control of battery SOC estimated by using an accurate algorithm. The action of the PID regulators appears to be adequate in order to avoid the intervention of the protection relays of the battery inverter also for the case of critical load rejection manoeuvres.

The estimation of the battery SOC represents a key parameter for the management of the energy flows in a stand-alone system equipped with multiple power supply and electrochemical batteries. The experimental results presented in this paper regard both the dynamic characterization of a $4.5 \mathrm{~kW}$ PEM FC and of a $100 \mathrm{Ah}$ lead-acid battery storage system. In this respect, the obtained results appear to be an interesting complement of those recently presented in the literature by other Authors (e.g., Uzunoglu, et al., 2007 and Tang, et al., 2010) that are mainly focused on the analysis of the FC characteristics.

The described PMS does not include a load forecast tool and load control strategies. The inclusion of these additional components is the objective of future steps of the research project, which also aims at investigating the most suitable approaches in order to exploit the heat production capability of the FC unit and at optimizing the system efficiency of the hybrid power supply.

\section{ACKNOWLEDGMENTS}

The authors warmly thank Prof. Carlo Alberto Nucci for his useful comments on the manuscript and Martina Ubaldi for her help during the experimental tests.

\section{REFERENCES}

Belvedere, B., Bianchi, M., Borghetti, A. and Paolone, M. (2009). A microcontroller-based automatic scheduling system for residential microgrids. Proc. of 2009 IEEE Power Tech Conference, Bucharest.
Britton, Lunscher, and Tanju. (1993). A 9-KW HighPerformance Solar Array Simulator. Proc. of the European Space Power Conference.

Erdinc, O., Uzunoglu, M. (2010). Recent trends in PEM fuel cell-powered hybrid systems: Investigation of application areas, design architectures and energy management approaches. Renewable and Sustainable Energy Reviews, 14, 2874-2884.

Jain S., Agarwal V. (2008). An Integrated Hybrid Power Supply for Distributed Generation Applications Fed by Nonconventional Energy Sources. IEEE Trans. on Energy Conversion, 23, 622-631.

Jiang W., Fahimi, B. (2010). Active current sharing and source management in hybrid power. IEEE Trans. on Industrial Electronics, $57,752-761$.

Linden, D. (1995). Handbook of Batteries. New York: McGraw-Hill.

Maclay, J.D., Brouwer, J., Samuelsen, S. G. (2006). Dynamic analyses of regenerative fuel cell power for potential use in renewable residential applications. Int. Journal of Hydrogen Energy, 31, 994-1009.

Maclay, J.D., Brouwer, J., Samuelsen, S. G. (2007). Dynamic modeling of hybrid energy storage systems coupled to photovoltaic generation in residential applications. Journal of Power Sources, 163, 916-925

Piller, S., Perrin, M., Jossen, A. (2001). Methods for state-ofcharge determination and their applications, Journal of Power Sources, 96, 113-120.

Pop, V., Bergveld, H.J., Notten, P.H.L., Regtien, P.P.L. (2005). State-of-the-art of battery state-of-charge determination, Measurement Science and Technology, Vol. 16, R93-R110.

Sammes, N.M., Boersma, R. (2000). Small-scale fuel cells for residential applications. Journal of Power Sources, 86, 98-110.

Strauss, Ph., Engler, A. (2003). AC coupled PV hybrid systems and Microgrids - State of the Art and Future Trends. Proc. of 3rd World Conf. on Photovoltaic Energy Conversion, Osaka, Japan.

Tang, Y., Yuan, W., Pan, M., Li, Z. Chen, G., Li, Y. (2010). Experimental investigation of dynamic performance and transient responses of a $\mathrm{kW}$-class PEM fuel cell stack under various load changes. Applied Energy, 87, 14101417.

Thounthong, P., Raël, S., Davat, B. (2008). Control Algorithm of Fuel Cell and Batteries for Distributed Generation System, IEEE Trans. on Energy Conversion, 23, 148-155.

Uzunoglu, M., Onar, O.C., Alam, M.S. (2007). Dynamic behavior of PEM FCPPs under various load conditions and voltage stability analysis for stand-alone residential applications. Journal of Power Sources, 168, 240-250. 